\title{
MAKSİLLADA AÇILI İMPLANTLAR KULLANILARAK YAPILAN İMMEDİAT YÜKLEMENİN KISA DÖNEM SONUÇLARI
}

\author{
THE MIDDLE PRELIMINARY RESULTS OF IMMEDIATE LOADING USING TILTED \\ IMPLANTS IN MAXILLA
}

\author{
Dr. Öğr. Üyesi Muzaffer ASLAN *
}

Makale Kodu/Article code: 3853

Makale Gönderilme tarihi: 15.10 .2018

Kabul Tarihi: 23.10 .2019

Muzaffer Aslan: ORCID ID: 0000-0002-2418-9472

DOI : $10.17567 /$ ataunidfd.636943

\section{öz}

Amaç: Bu çalışmada, dişsiz maksillaya uygulanan doğrusal ve eğik implantlar üzerine immediat yüklemenin orta dönem komplikasyonlarını değerlendirmektir.

Mteryal ve Metod: 18 hasta ( 8 kadın ve 10 erkek) çalışmaya alındı. Her hastaya iki doğrusal ve iki açılı implant ile desteklenen bir immediat sabit protez takıldı. Toplam 72 implant yerleştirildi. Ameliyattan 24 saat sonra yükleme yapıldı ve 6 ay sonra daimi protezler yapıldı. Hastalar $6,12,24,36$. aylarda olmak üzere takip edildi. Her takipte ağız hijyeni kontrol edildi ve her komplikasyon kaydedildi.

Bulgular: Hiçbir implant kaybı görülmezken (\%100 sağkalım oranı), bazı hastalarda mukozitis $(\% 22,2)$ ve periimplantitis $(\% 11,1)$ kaydedildi. En sık görülen protetik komplikasyonlar, \%33,3 oranında görülen geçici protez fraktürü idi. Hijyenik problemler \% 44,4 hastada görüldü ve bunun yanısıra hiçbir hasta memnuniyetsizliği kaydedilmedi.

Sonuç: İmplant sağkalım oranının yüksek olması, açıı implantların kullanımının iyi bir seçenek olabileceğini göstermektedir. Bu sayede greft maliyeti olmamakta ve augmentasyon operasyonlarına da gerek duyulmamaktadır. Çalışmamızda ayrıca, implant ve protez ile ilgili sorunları önlemek için hastaların rutin kontrolünün ve sorunun erken tespitinin önemli olduğu görülmektedir. Anahtar Kelimeler: Açlı implantlar, immediat implantasyon, immediat yükleme.

\section{SUMMARY}

Objective: The aim of this study was to evaluate the mid-term complications of immediate loading on axial and tilted implants placed to edentulous maxilla.

Materials and Methods: Eighteen patients (8 females and 10 males) were included in the study. Immediately loaded fixed prosthesis supported by two axial and two tilted implants were performed for each patient. A total of 72 implants were placed. Loading was performed 24 hours after the operation and final prosthesis was performed after 6 months. Patients were followed up at 6, 12, 24 and 36 months. Oral hygiene was checked at each follow-up and all complications were recorded.

Results: No implant loss (100\% survival rate), mucositis (22.2\%) and periimplantitis $(11.1 \%)$ were recorded in some patients. The most common prosthetic complication was temporary prosthetic fracture with a rate of $33.3 \%$. Hygienic problems were seen in $44.4 \%$ of patients and no patient dissatisfaction was recorded.

Conclusion: According the results of the study, use of angled implants may be a good option. In this method, there is no graft cost and augmentation is not required. In our study, it is seen that routine control of the patients and early detection of the problem are important in order to prevent problems related to the implant and prosthesis.

Key Words: Tilted implants, immediate implantation, immediate loading.

* Özel Adana Akademi, Ağız ve Diș Sağlığı Merkezi, Adana, Türkiye

Kaynakça Bilgisi: Aslan M.Maksillada Açlı İmplantlar Kullanılarak Yapılan İmmediat Yüklemenin Kısa Dönem Sonuçları. Atatürk Üniv Diş Hek Fak Derg 2020; 30 : 75-82. Citation Information: Aslan M.The Middle Preliminary Results of Immediate Loading Using Tilted Implants in Maxilla. J Dent Fac Atatürk Uni 2020; 30: 75-82. 


\section{GİRIŞ}

Uzun takipli bazı çalışmalar, atrofik çenelerde yapılan implant destekli tam ark restorasyonlarda yüksek başarı ve sağkalım oranları bildirmiştir. ${ }^{1}{ }^{2}$ Bu tür planlamalarda implantlar çenelerin orta bölgesine yerleştirilmektedir. Bu mandibulada iki mental foramen arası olurken maksillada ise sinüslerin arasına uygulanmaktadır. Bu protez sistemlerine distal kanat da eklenmektedir.

Atrofik maksilla vakalarına implant yerleştirebilmek için greftleme ve sinüs lifting prosedürleri etkili olsa da, ${ }^{3},{ }^{4}$ literatürde bazı komplikasyonların geliştiği rapor edilmiştir. ${ }^{5}$ Bu sebeple açוlı implant uygulamalarının hem kemik augmentasyon prosedürleri gerektirmemesi hem de cerrahi sırasında önemli anatomik yapılara uzak çalışılması nedeniyle iyi bir yöntem olarak sunulmuştur. ${ }^{6}$ Ayrıca, distal implantların açılı yapılması implantlar arasındaki mesafenin arttırımasına ve böylece kanat uzunluğunun da azaltılmasını sağlar. ${ }^{78}$

"All on four" prosedürü herhangi bir kemik augmentasyon prosedürüne gerek kalmadan dişsiz çeneleri rehabilite etmek için önerilmiştir. ${ }^{9},{ }^{10}$ Distaldeki implantlar, mümkünse maksiller sinüsün ön duvarlarıyla temas halinde ve sinüs membranı rüptürü olmadan yerleştirilmelidir. ${ }^{11} \mathrm{Bu}$ prosedür, hem kısa hem de orta dönemdeki başarısı nedeniyle literatürde kabul görmüştür. ${ }^{8},{ }^{10}, 1{ }^{-14}$

Bu çalışmanın amacı, açılı ve doğrusal implantların kullanılarak, immediat yüklenmiş tam ark maksiller protezlerin orta dönem kullanımlarında ortaya çıkan komplikasyonları araştırmak ve sunmaktır.

\section{MATERYAL VE METOD}

Çalışmamıza 18 yaşından büyük ve genel sağlık durumlarında operasyona engel bir durumu (pıhtılaşma sorunları, immün sistem hastalıkları, kontrolsüz diabet, kemiği etkileyen metabolik hastalıklar, hamilelik, son 5 yı içinde alınmış kemoterapi veya radyoterapi durumları) olmayan hastalar edildi. Hastaların maksillaları tam dişsizdi veya prognozu kötü dişleri vardı. Sinüsler arası bölgede $10 \mathrm{~mm}$ boy ve $4 \mathrm{~mm}$ çapta implant yerleştirilebilecek uygunlukta kemik hacmi olmasına dikkat edildi. Molar bölgeleri atrofikti ve implant uygulanabilmesi için sinüs lifting operasyonu ve greftleme gerekliydi. İşlem bölgesinde akut enfeksiyon olmamasına da ayrıca dikkat edildi.

Hastaların klinik muayenesi sırasında ortopantomograf (OPG) ve bilgisayarlı tomografi (CT) alındı. Anamnezine göre ihtiyaç duyulan hastalardan kan testleri ve konsultasyonlar istendi.

Operasyondan önce hastaların ölçüleri ve kapanışları alınarak dikey boyutları belirlendi. Varsa çekilecek dişleri modelden kazınarak model üzerinde birer total protez hazırlandı ve protezin içi boşaltılıp kabuk haline getirildi (Resim 1-6).

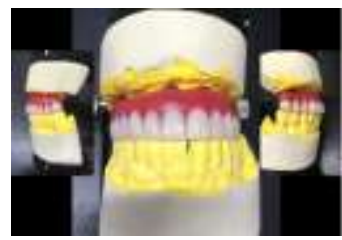

Resim 1.

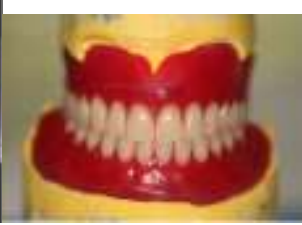

Resim 2.

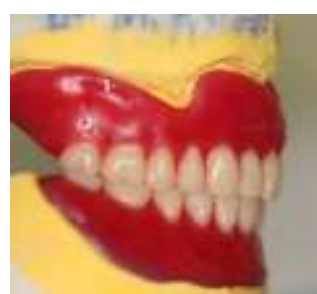

Resim 3.

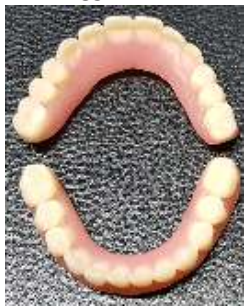

Resim 4.

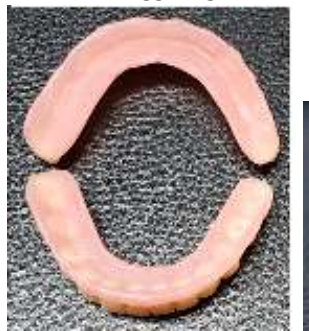

Resim 5.

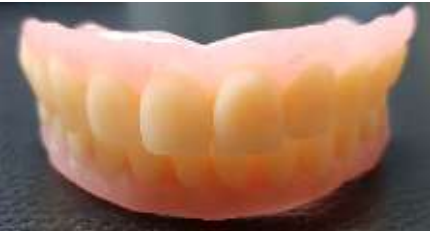

Resim 6.
Resim 1-6. Operasyon öncesi geçici immediat protezin hazırlanması.

Tüm ameliyatlar intravenöz sedasyon ve lokal anestezi altında yapıldı. Birinci molar diş hizasından, diğer birinci molar diş hizasına kadar kret tepesinden geçen bir insizyon yapıldı. Mevcut olan prognozu kötü tüm dişler çekildi ve soketler kürete edildi. İki adet distal implant okluzal düzleme yaklaşık 30 derece açılı, 
iki anterior implant da dik olacak şekilde yerleştirildi. Böylece her maksillaya dört implant (Straumann Roxolid, Bone Level Tapered, Basel, Switzerland) uygulandı. İmmediat yükleme yapılabilmesi için implantlar $50 \mathrm{Ncm}$ 'lik bir torkla yerleştirildi. İmplantlara eksenlerine ve protezde açılacak vida çıkış delikleri de göz önüne alınarak 17 veya 30 derece açılı multi-unit abudmentler takıldıktan sonra plastik kepler takıldı ve dokular sütüre edildi (Resim 7-9). Operasyondan önce hazırlanmış ve içi boşaltılmış üst total protez dezenfekte edilip içine ikinci ölçü maddesi yerleştirilerek maksillaya adapte edildi. Böylece protezin içindeki ölçü üzerinde implantların yerleri belirlenmiş oldu. Bu izlerin rehberliğinde protezde abudmentler için delikler açıldı. Sonra plastik kepler çıkarılıp geçici abudmentler takıldı (Resim 10), ve protez tekrar adapte edilerek kontrol edildi (Resim 11). Protez enjektabl rezin ile abudmentlere sabitlendikten ve rezin sertleştikten sonra (Resim 12) abudment vidaları sökülerek protez çıkarıldı. Tesfiye ve cilası yapıldıktan sonra (Resim 13) dezenfekte edilip $15 \mathrm{Ncm}$ 'lik bir tork ile implantlar üzerine vidalandı (Resim 14-15). Vida delikleri önce teflon sonra rezinle kapatıldı. Okluzyon kontrolünden sonra hastalar ilaç tedavisi önerilip taburcu edildi. Postoperatif yedi gün boyunca her 12 saatte bir antibiyotik (Amoksisilin ve Klavulanik asit $1 \mathrm{~g}$ ), analjezik (Filurbiprofen 100 mg) ve ağız gargarası (Klorheksidin Diglukonat\% 0.2) kullanılması önerildi. Hastalara ilk ay yumuşak-sıvı ağırlıklı diyetle beslenmesi telkin edildi. İlk ay boyunca her hafta yapılan kontrollerde doku iyileşmesi, protezin fonksiyonu ve ağız hijyeni değerlendirildi. Sonraki 6. aya kadar her ay bu kontrollere devam edildi. Her ziyarette protez mobilitesi ve okluzyon kontrol edildi. 6 aylık süre sonunda metal iskelet, porselen dişler ve kompozit dişeti bölümlerinden oluşan daimi hibrit protezleri yapıldı. Daimi protezden sonra 6 ayda bir kontrollere çağrıldı. Ağız hijyeni ve komplikasyonlar değerlendirildi. Örnek vakaların çalışma aşamaları fotoğraflarla gösterilmiştir (Resim 16-47).

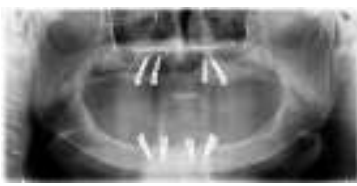

Resim 7.

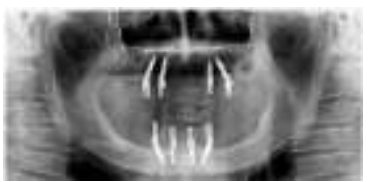

Resim 8.

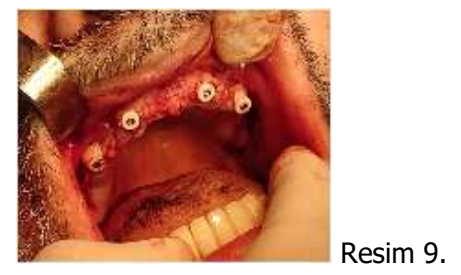

Resim 7-9. implantların ve açılı multi abudtmentların takılması.

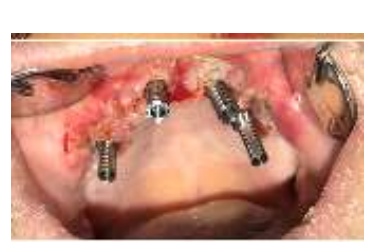

Resim 10.

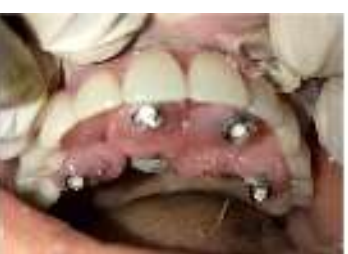

Resim 12.

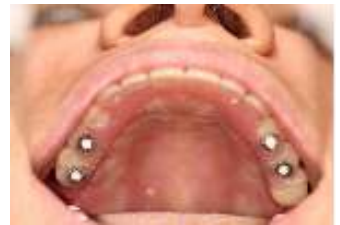

Resim 14.

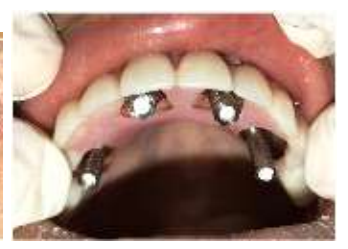

Resim 11.

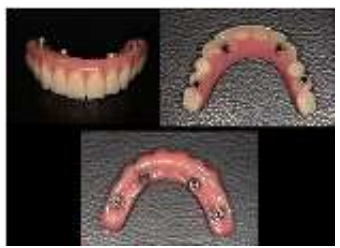

Resim 13.

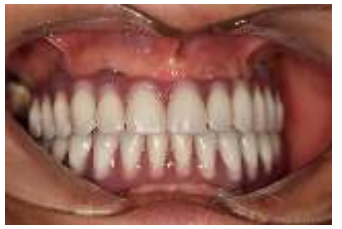

Resim 15.
Resim 10-15. Geçici protezin ağıza uygulanması ve kapanış kontrolü.

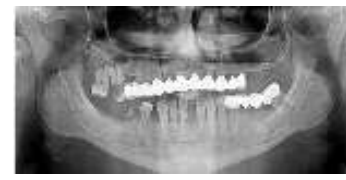

Resim 16

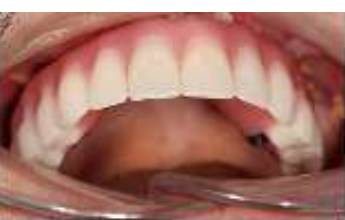

Resim 18.

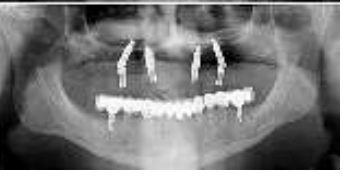

Resim 17.

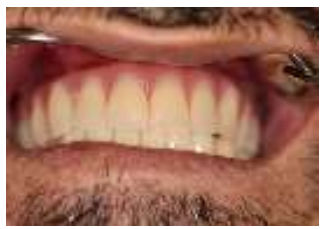

Resim 19. 


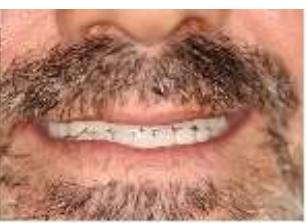

Resim 20.

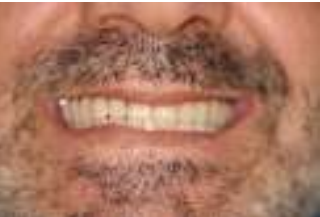

Resim 22.

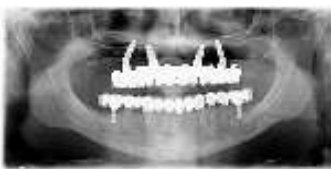

Resim 24.

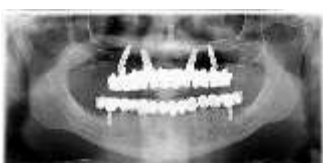

Resim 26.

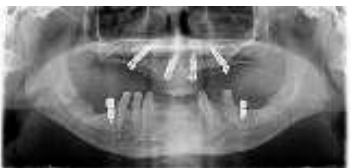

Resim 28

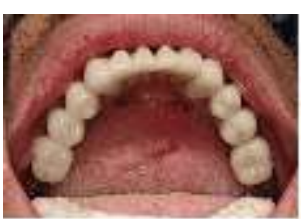

Resim 30 .

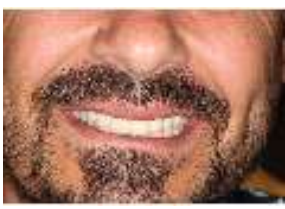

Resim 32.

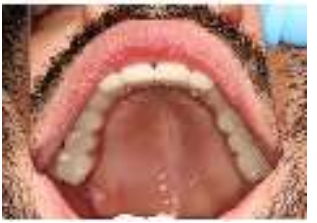

Resim 31

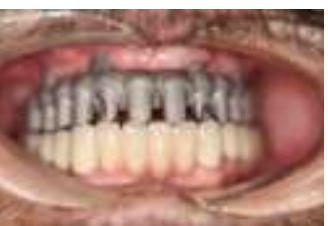

Resim 21.

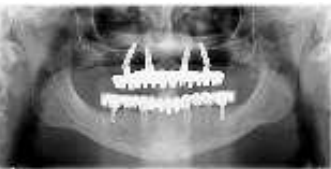

Resim 23.

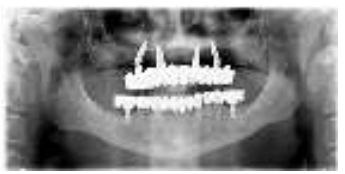

Resim 25.

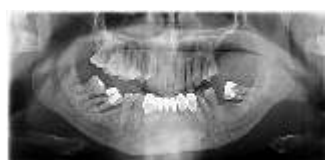

Resim 27.

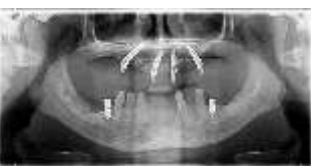

Resim 29.

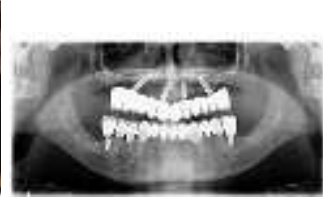

Resim 33

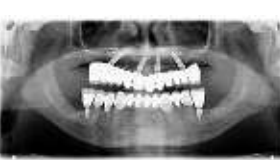

Resim 34.

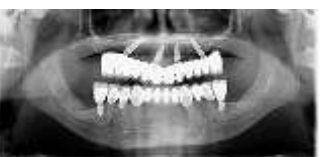

Resim 36

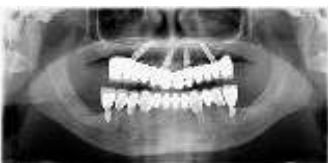

Resim 35.

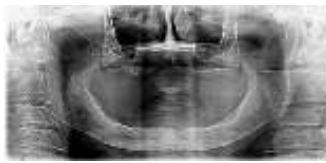

Resim 37.

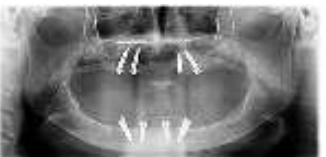

Resim 38.

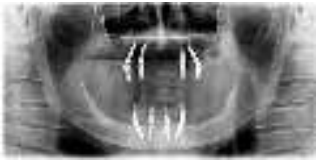

Resim 39.
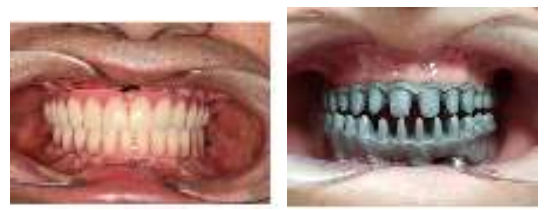

Resim 40. Resim 41.
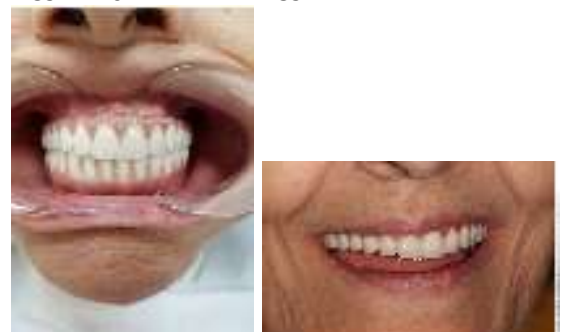

Resim 42.

Resim 43.

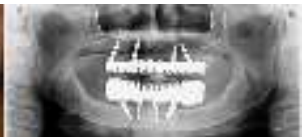

Resim 44

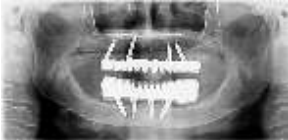

Resim 46.

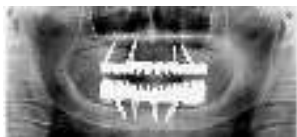

Resim 45.

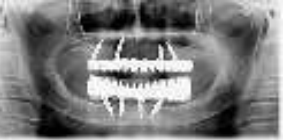

Resim 47.
Resim 16-47. Örnek vakaların tedavi aşamaları. 


\section{SONUÇLAR}

Temmuz 2014'den Temmuz 2017'ye kadar, toplam 18 sağlıklı hastaya (8 kadın ve 10 erkek; ort. Yaş 60,83 yıl), maksiller dört implant üzerine immediat yüklenen sabit protez yapıldı. Toplam 72 implant yerleştirildi (uzunluk; $10 \mathrm{~mm}$ ile $14 \mathrm{~mm}$ arasında). Bunların 36'sı aksiyel, 36'sı yaklaşık 30 derece eğimlidir. Tüm implantların çapı 4,1 mm idi. Operasyondan sonra en geç 24 saat sonra hastaların sabit geçici protezleri takıldı. Vakalar 14-36 ay aralığında (ortalama 27,2 ay) takip edildi. Çalışma boyunca implant kaybı görülmediği için implant sağkalım oranı\% 100'dür. Bununla birlikte 4 hastada (\% 22,2 oranında) alveolar mukozit, 2 hastada (\% 11,1) periimplantitis kaydedildi. En sık görülen protez komplikasyonu, geçici akrilik protezde meydana gelen kırılma veya diş ayrılmasıdır (7 hastada ve \% 33,3). 1 hastanın daimi protezinde proselen kırılması görülmüştür (\% 5,5 oranında). Üç hastada da protez vidası gevşemesi kaydedildi (\% 16,6 oranında). 11 hastada hijyenik sorunlar (\% 44,4 oranında) görüldü, ancak bu problemler daha iyi bir ağız hijyeni motivasyonuyla ve daha sık takip edilerek, ilerlemeden çözüldü. Hiçbir hasta memnuniyetsizliği kaydedilmedi.

Çalışma boyunca karşılaşılan komplikasyonların oranları Tablo 1' de gösterilmiştir.

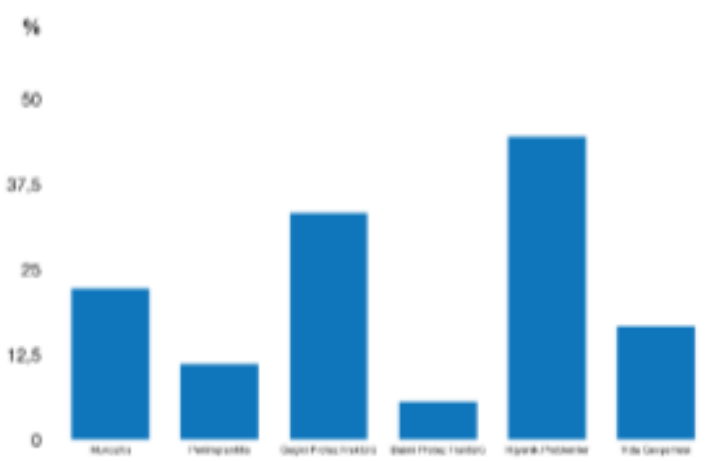

Tablo 1. Komplikasyon oranları grafiği.

\section{TARTIŞMA}

Bu çalışmada, dişsiz maksillalarına 4'er implant yapılarak immediat yüklenen bir grup hastanın orta dönem takip sonuçları ve komplikasyonları bildiril- miştir. Tüm implantlar \% 100 sağkalım oranı gösterdi ancak bununla birlikte bazı protetik ve hijyenik komplikasyonlar meydana geldi. Literatürde implant destekli bir rehabilitasyonun etkinliğini değerlendirmek için en fazla bildirilen sonuç sağkalım (survival rate) oranıdır. İmplant başarısının değerlendirilmesi (success rate) için yaygın olarak kabul edilen kriterler fonksiyonda ağrı olmaması, klinik mobilize olmaması, 2 mm'den daha az radyolojik kemik kaybı ve eksüda olmaması olarak değerlendirildi. ${ }^{15-17}$

Çalışmamızda implant sağkalım oranı\% 100 iken, periimplantitis görülen implantlar hesaba katıldığında başarı oranı (success rate) \% 97.2 bulunmuştur.

144 implant ile yapılan ve 10 yıllık takip sonuçlarını içeren bir çalışmada sağkalım oranı \%95,1'dir. Çalışmada ayrıca tüm başarısızlıkların ilk 2 yılda ortaya çıktığı rapor edilmiştir. ${ }^{18}$

Atrofik maksillalara uygulanan açılı ve düz implantlarla yapılan biyomekanik bir çalışmanın sonuçlarında açılı implantlarda düz implantlara göre daha yüksek stres değerleri tespit edilmiştir. ${ }^{19}$ Ayrıca Hamed ve ark maksilla posterior bölgeye uygulanan açılı implantların düz olanlara göre \% 66 oranında daha yüksek stres aldığını göstermişlerdir. ${ }^{20}$ Bunun yanında, 1849 hastaya uygulanan 7568 implantın 3 yıllık takip verilerinin sunulduğu bir çalışmada; sağkalım oranı ve marjinal kemik kaybı yönünden düz ve açlı implantlar arasında bir fark bulunamamıştır. ${ }^{21}$

Son zamanlarda bazı yazarlar herhangi bir protez başarısızlığı olmaksızın 24 hastanın maksiler implant destekli tedavisi için 3 yıllık takipte implant sağkalım oranının \% 98.96 olarak bildirmişlerdir. ${ }^{22} 276$ hasta üzerinde yapılmış bir çalışmada, protezin yerleştirilmesinden 16 ay sonra yapılan değerlendirme sonucunda bu tekniğin performansının oldukça iyi olduğunu bildirmişlerdir. ${ }^{23}$

Babbush ve arkadaşları tarafından yapılan retrospektif bir araştırmada, 29 aylık takip sonucu implant sağkalım oranı \% 99.3 olarak tanımlanmıştır. Ayrıca bu çalışmada final protezin başarı oranı\% 100 'dür. ${ }^{13}$

21 hastaya 70 implant uygulanarak yapılan bir çalışmada implantlar düz ve açılı olarak yerleştirilmiş ve 2 yıllık takibin sonunda sağkalım oranı \%100 olarak kaydedilmiştir. Çalışmanın sonucunda maksiller posterior bölgede düz ve açılı implantların üzerine 
vidalı olarak yapılan protezlerin oldukça güvenilir olduğu belirtilmiştir. ${ }^{24}$

Apaza ve ark çalışmalarında düz ve açılı implantları 3 yıl takip ederek karşılaştırmış ve implant sağkalım oranı ile periimplant kemik kaybı açısından aralarında farklılık olmadığını belirtmişlerdir. ${ }^{25}$ Testori ve ark 27 hastada uygulanan düz ve açılı implantları 2 yıl takip etmişlerdir. Açılı implant uygulamasının güvenilir olduğu ve hasta memnuniyet anketi açısından oldukça iyi bir prosedür olduğunu rapor etmişlerdir. ${ }^{26}$ Gintaute ve ark açılı ve düz implantları karşılaştırdıkları çalışmalarında açılı implant uygulamasının özellikle fullark kullanımlarda tavsiye edilebilir bir yöntem olduğunu söylemişlerdir. ${ }^{27}$ Malo ve ark 5-13 yıllık takip verilerini içeren çalışmalarında maksillaya uygulanan açılı implantların uzun vadede oldukça güvenilir bir yöntem olduğunu belirtmişlerdir. ${ }^{28}$ Penaloza ve ark 728 çalışmayı gözden geçirerek hazırladıkları makalede düz ve açılı implantlarla yapılan "all on four" prosedürünün oldukça güvenilir olduğunu ve rejeneratif greftleme yöntemleri gerektirmemesi nedeniyle de avantajlı olduğunu belirtmişlerdir. ${ }^{29}$

Malo ve ark. tarafından yayınlanan bir başka retrospektif çalışmada, iki eğimli ve iki aksiyel implant ile tedavi edilen 242 hasta hakkındaki veriler rapor edilmiştir. 5 yıllık implant sağkalım oranı\% 98, protez başarısı oranı \% 100'dür. Sadece birkaç küçük protez komplikasyonu bildirilmiştir. ${ }^{10} \mathrm{Bu}$ sonuçlar tekniğin ve klinisyenlerin zamanla daha da geliştiğini göstermektedir.

Çalışmamızda da en sık görülen protez komplikasyonu, özellikle geçici protezde görülen fraktürlerdi. Daimi protezlerden birinde az da olsa porselen dişlerde kırılmalar görüldü. Ancak bunlar implant seviyesinde majör sorunlara neden olmadı. Ayrıca \%16,6 oranında protez vidası gevşemesi görüldü. Bunun da protetik vida torklama kitinin kalibrasyonu ile ilgili olabileceği düşünmekteyiz. Bu nedenle de torklama kitlerinin düzenli olarak kalibrasyonlarının yapılması gerekmektedir.

Çalışmamızda hijyenik problemlerin oranı nispeten yüksektir $(\% 44,4)$. Bu konu oldukça önemlidir, çünkü implantı çevreleyen yumuşak doku sağığının korunması başarı için çok gereklidir. ${ }^{30} \mathrm{Bu}$ nedenle, uzun süreli bakımda hijyenik sorunların sıkı bir şekilde kontrol edilmesi zorunludur.
Çalışmamızın sonuçlarında hijyenik veya protetik komplikasyonlara rağmen tüm implantların hayatta kaldığını görüyoruz. Bu da kontrol ve takip programının etkili olduğunu, komplikasyonların başlangıçta ve büyümeden çözülmesini sağladığını göstermektedir. Hastaların ağız hijyeni motivasyonu düzenli randevu protokolleriyle kontrol edilmelidir.

İmplant tedavileri bitiminde yapılan hasta memnuniyeti çalışamalarında, hastaların büyük çoğunluğu fonksiyon, fonasyon ve estetik açıdan tedaviden memnun kalmışlar fakat tedavi maliyetleri konusunda memnuniyetsizliklerini dile getirmişlerdir. ${ }^{31}$ Çalışmamızdaki tedavi protokolünde greft kullanımı ve sinüs lifting gibi ilave operasyon masrafları olmadığı için ekonomik yönden de avantajı bir durum oluşturmaktadır.

Sonuç olarak, bu çalışma, atrofik maksillaları rehabilite etmek için açılı implantların kullanımının, posterior alandaki kemik augmentasyon prosedürlerine iyi bir alternatif olabileceğini, iyi bir fonksiyon ve estetik sağlayarak yüksek hasta memnuniyeti oluşturduğunu göstermiştir. Ancak olası komplikasyonlar, yapılan kontrollerde tespit edilip erken müdahale edilerek düzeltilmelidir.

NOT: Çalışmada herhangi bir yazar, kurum ya da kuruluş ile çıkar çatışması içerisinde bulunmamaktadır. Makale daha önce hiçbir yerde yayınlanmamış ve yayınlanmak üzere işlem görmemektedir

\section{KAYNAKLAR}

1. Adell R, Eriksson B, Lekholm U, Bra nemark PI, Jemt T. Long-term follow-up study of osseointegrated implants in the treatment of totally edentulous jaws. Int J Oral \& Maxillofac Imp 1990; 5, 347- 59.

2. Jemt $T$, Johansson J. Implant treatment in the edentulous maxillae: a 15-year follow-up study on 76 consecutive patients provided with fixed prostheses. Clin Imp Dent Related Res 2006; 8: 61-9.

3. Wallace SS, Froum SJ. Effect of maxillary sinus augmentation on the survival of endosseous dental implants. A systematic review. Ann Periodontol 2003; 8: 328-43. 
4. Del Fabbro M, Rosano G, Taschieri S. Implant survival rates after maxillary sinus augmentation. Eur J Oral Sci 2008; 116: 497-506.

5. Katranji A, Fotek $P$, Wang HL. Sinus augmentation complications: etiology and treatment. Implant Dentistry 2008; 17: 339-49.

6. Krekmanov L, Kahn M, Rangert B, Lindstro " $\mathrm{m} \mathrm{H}$. Tilting of posterior mandibular and maxillary implants for improved prosthesis support. International Journal of Oral and Maxillofacial Implants 2000; 15: 405-14.

7. Bellini CM, Romeo D, Galbusera F, et al. A finite element analysis of tilted versus nontilted implant configurations in the edentulous Maxilla. Int J Prosthodont 2009; 22: 155-7.

8. Francetti L, Romeo D, Corbella S, Taschieri S, Del Fabbro $M$. Bone level changes around axial and tilted implants in full-arch fixed immediate restorations. Interim results of a prospective study. ClinImpDent Related Res 2012; 14: 64654.

9. Malo P, Rangert B, Nobre M. All-on-4 immediatefunction concept with Branemark system implants for completely edentulous maxillae: a 1year retrospective clinical study. Clin Imp Dent Related Res 2005; 7 supp: 88-94.

10. Malo $P$, de Araujo Nobre M, Lopes A, Francischone $C$, Rigolizzo $M$. "All-on-4" immediate-function concept for completely edentulous maxillae: a clinical report on the medium (3 years) and long-term (5 years) outcomes. Clin Impl Dent Related Res 2012; 14: 139-50.

11. Jensen OT, Adams MW, Cottam JR, Parel SM, Phillips WR. The all-on-4 shelf: maxilla. J Oral Maxillofac Surg 2010; 68: 2520-7.

12. Francetti L, Agliardi E, Testori T, Romeo D, Taschieri S, Fabbro MD. Immediate rehabilitation of the mandible with fixed full prosthesis supported by axial and tilted implants: interim results of a single cohort prospective study. Clin Imp Dent Related Res 2008; 10: 255-63.

13. Babbush CA, Kutsko GT, Brokloff J. The all-onfour immediate function treatment concept with NobelActive implants: a retrospective study. J Oral Implantol 2011; 37: 431-45.
14. Penalosa DS, Alonso RZ, Diago MP, Diago MP. The all-on-four treatment concept: Systematic review. J Clin Exp Dent 2017;9: 474-88.

15. Albrektsson $T$, Zarb G, Worthington P, Eriksson AR. The long-term efficacy of currently used dental implants: a review and proposed criteria of success. Int J Oral \& Maxillofac Imp 1986; 1 : 11-25.

16. Misch $\mathrm{CE}$, Perel $\mathrm{ML}$, Wang $\mathrm{HL}$, et al. Implant success, survival, and failure: the International Congress of Oral Implantologists (ICOI) pisa consensus conference. Imp Dent 2008; 17: 5-15.

17. Kürkçüoğlu I, Köroğlu A, Özkır SE. Dental implantlarda başarı kriterleri ve başarı değerlendirme yöntemleri. Atatürk Üniv Diş Hek Fak Derg. 2010; 20:3:221-9.

18. Testori T, Galli F, Fumagalli L, Capelli M, Zufetti $F$, Deflorian $M$, Parenti A, DelFabbro $M$. Assessment of long-term survival of immediately loaded tilted implants supporting a maxillary fullarch fixed prosthesis. Int J Oral Maxillofac Imp 2017; 32: 904-11.

19. Gümrükçü $Z$, Korkmaz $Y T$, Korkmaz FM. Biomechanical evaluation of implant-supported prosthesis with various tilting implant angles and bone types in atrophic maxilla: A finite element study. Comput Biol Med. 2017; 1:47-54.

20. Hamed HA, Marzook HA, Ghoneem NE, El-Anwar MI. Angulated dental implants in posterior maxilla FEA and experimental verification. Open Access Maced J Med Sci. 2018; 6: 397-401.

21. Alccayhuaman KAA, Penalosa DS, Nakajima Y, Papagergiou SN, Boticelli D, Lang NP. Biological and technical complications of tilted implants in comparison with straight implants supporting fixed dental prosthesis. A systematic review and meta-analysis. Clin Oral Implants Res 2018; 29 Suppl 118: 295-308.

22. Crespi R, Vinci R, Cappare' P, Romanos G E, Gher- lone E. A clinical study of edentulous patients rehabilitated according to the "all on four" immediate function protocol. The International Journal of Oral \& Maxillofacial Implants 2012; 27: 428-34. 
23. Graves S, Mahler BA, Javid B, Armellini D, Jensen OT. Maxillary all-on-four therapy using angled implants: a 16- month clinical study of 1110 implants in 276 jaws. Dental Clinics of North America 2011; 55: 779-794.

24. Epinosa JCC, Oyagüe RC, Figallo MA., Serrano RG, Lynch CD, Collar MM, Lagares DT, Perez JLG. Combination of straight and tilted implants for supporting screw-retained dental prostheses in atrophic posterior maxillae: A 2-year prospective study. J Dent 2017;63:85-93.

25. Apaza Alccayhuaman KA, Soto-Penaloza $D$, Nakajima Y, Papageorgiou SN, Boticelli D, Lang NP. Biological and technical complications of tilted implants in comparison with straight implants supporting fixed dental prostheses. A systematic review and meta-analysis. Clin Oral Implants Res. 2018; 29 Suppl 18: 295-308.

26. Testori T, Galli F, Fumagalli L, Capelli M, Zufetti F, Deflorian M, Parenti A, Del Fabbro M. Assessment of long-term survival of immediately loaded tilted implants supporting a maxillary fullarch fixed prosthesis. Int J Oral Maxillofac Implants 2017; 32: 904-11.

27. Gintatue A, Papatriantafyllou N, Aljehani M, Att W. Accuracy of computerized and conventional impression-making procedures for multiple straight and tilted dental implants. Int J Esthet Dent 2018; 13: 550-65.

28. Malo P, de Araujo Nobre M, Lopes A, Ferro A, Nunes $M$. The All-on-4 concept for full-arch rehabilitation of the edentulous maxillae: $A$ longitudinal study with 5-13 years of follow-up. Clin Implant Dent Relat Res 2019 Mar 28 (Epub ahead of print).

29. Soto-Penaloza D, Zaragozi -Alonso R, Penarrocha-Diago $M$. The all-on-four treatment concept: Systematic review. J Clin Exp Dent 2017; 9: 474-88.

30. Corbella S, Del Fabbro M, Taschieri S, De Siena F, Francetti L. Clinical evaluation of an implant maintenance protocol for the prevention of periimplant diseases in patients treated with immediately loaded full-arch rehabilitations. International J Dent Hygiene 2011; 9: 216-22.
31. Ergun S, Çekici A, A.Saruhanoğlu, Kazancıoğlu O, Uzman A, Ak G, Tanyeri H. Dental implantlar ile rehabilite edilmiş hastaların memnuniyet derecelerinin değerlendirilmesi. Atatürk Üniv Diş Hek Fak Derg 2009; 19:3:181-6.

\section{Yazışma Adresi}

Dr.Öğr.Üyesi Muzaffer ASLAN

Özel Adana Akademi

Ağız Ve Diş Sağlıği Merkezi

Kurtuluş mah. Cumhuriyet cad. No:48

MNS Plaza Zemin Kat.

Seyhan - ADANA 